\title{
Synthesis and Characterization of Porous Ceramic Hollow Fibers with Nano-Molecular Size
}

\author{
Hussein Qasim Hussein \\ Chemical Engineering, College of Engineering, University of Baghdad
}

\begin{abstract}
This research exhibits a method for the fabrication of nano molecular size ceramic porous hollow fibers, using the internal diffusion technique. This method is based on preparation a spinning solution consists from nano gamma alumina $<50 \mathrm{~nm}$ in an aqueous mixture of sodium alginate, and calcium carbonate. The mixture is spun into a lactic acid coagulation bath of $\mathrm{pH}=1.6$ to achieve ionic cross-linking. The green transparent ceramic hollow fibers were dried under ventilation at ambient temperature for $48 \mathrm{~h}$ and sintered at different temperatures $1100{ }^{\circ} \mathrm{C}-1350{ }^{\circ} \mathrm{C}$ for $2 \mathrm{~h}$. The synthesized fibers were characterized and the effect of sintering temperature on surface morphology was studied. The phase transformation from gamma to alpha was specified by $\mathrm{x}$-ray diffraction, at $1100{ }^{\circ} \mathrm{C}$ a few small and sharp peaks of $\alpha$-alumina started while at $1250{ }^{\circ} \mathrm{C} \alpha$-alumina with a highly crystalline structure was obtained. Microstructure and surface morphology of nano ceramic fibers were studied at different sintering temperatures, a homogeneous particle distribution was gained at a temperature of $1250{ }^{\circ} \mathrm{C}$. The thermal gravimetric analysis was referred to an existence of two thermal steps occurred during thermal treatment, dehydration up to 250 ${ }^{\circ} \mathrm{C}$ and alginate dehydration and decomposition from $250{ }^{\circ} \mathrm{C}$ to $400{ }^{\circ} \mathrm{C}$. The nitrogen isotherm behavior indicates to a mesoporous / macroporous substance, an appearance of type H-2 hysteresis loop. BJH adsorption and desorption average pore diameter (4V/A) $14.4408 \mathrm{~nm}$ and $17.7124 \mathrm{~nm}$ respectively. Single point surface area is $9.268 \mathrm{~m}^{2} / \mathrm{g}$, single point adsorption total pore volume is $0.023 \mathrm{~cm}^{3} / \mathrm{g}$. The average interior and exterior pore size by mercury intrusion were $20 \mathrm{~nm}$ and $50 \mathrm{~nm}$ respectively.
\end{abstract}

Keyword: membranes; hollow fibers; nano alumina; ionic gelation; internal setting 


\section{Introduction}

Hollow fiber manufacturing technology has evolved dramatically and became significant for various industrial applications, ceramic membranes synthesized from ceramic materials such as aluminum oxide $\left(\mathrm{Al}_{2} \mathrm{O}_{3}\right)$, silicon nitride $\left(\mathrm{Si}_{3} \mathrm{~N}_{4}\right)$, and silicon carbide $(\mathrm{SiC})$ have the thermal and chemical stability and high resistance to abrasion therefore possessed priority in application [1,2]

Ceramic membrane performance may exceeded other membrane systems due to the high surface area/volume ratios, mechanical resistance, and stability. These membranes can be used in several applications such as fabrication of solid oxide fuel cell [3], gas-liquid-solid microreaction technology [4], catalytic reactors [5,6], and porous ceramic microfiltration membranes [7,8]. Several methods have been applied for inorganic hollow fiber membranes synthesis like dry spinning [9,10], wet spinning [2], phase inversion [11-13], and bio-ionic gelation $[14,15]$.

The investigation to produce quite dense nanostructured ceramics has received much interest over the recent years because of the promise of nanograined materials with novel and enhanced properties [16]. One of the main difficulties of nanograined ceramics has been in the difficulty of processing nanosized powders and fabricating dense components. When attempt to achieve dense ceramics, grain growth out of the nanometer scale is oftentimes hard to avoid [17] and microstructures are not finer than traditional sub-micron processed ceramics.

Considerably, the onset nanopowder is not the thermodynamically stable phase and there are phase transformations during the densification process. One main factor in the densification of nanopowder is to trigger inter-agglomerate densification and to avoid a dominance of intra-agglomerate densification, which permit large stable pores in the final segment. [18]

It is tricky to gain a dense ceramic with nanocrystalline grain size because change in phase occurs during the conventional sintering at atmospheric pressure. The transformation of alumina phase involves a chance in the oxygen sublattice from cubic to hexagonal close packing and decrease in specific volume. The volume reduction and low nucleation density leads to $\alpha-\mathrm{Al}_{2} \mathrm{O}_{3}$ colonies retreat from the matrix and the microstructure evolves into vermicular morphology containing larger scale interconnected porosity [19]. The vermicular microstructure required high sintering temperatures over $1600^{\circ} \mathrm{C}$. 
Investigations had been done for sintering nanopowder at high pressures to avoid vermicular structure, high pressure promotes sufficient nucleation sites which reduces sintering temperatures required. Grain growth is limited at low sintering temperatures and high nucleation in $\gamma$ phase at high pressure creates a nano size $\alpha$ grain [20].

Several inorganic hollow fibers have been synthesized, from materials including alumina. The fibers have been prepared via a two-step approach. The first step is entails dry-wet spinning of a particle- loaded polymer solution. In the second step, the organic polymer is burned out and the inorganic particles are sintered [14].

In another hand, a route for the fabrication of porous inorganic hollow fibers using ecologically benign feed materials instead of organic solvents and harmful additives was investigated. The approach is based on bio-ionic gelation of an aqueous mixture of inorganic particles and sodium alginate during wet spinning. [21, 22].

A later development for fabrication of inorganic porous hollow fibers is based on ionic cross-linking of an aqueous mixture of sodium alginate, inorganic particles, and a carbonate. The mixture is spun into an acidic coagulation bath, where the low $\mathrm{pH}$ triggers the dissociation of the carbonate into multivalent cations and carbon dioxide. [15]

The objective of this research is synthesis nano alumina hollow fibers using bio-ionic gelation-internal setting method for crosslinking of sodium alginate chains by calcium ions under circumstance of acidity. Thermal treatment conditions, microstructure and surface morphology, isotherm type, and pore size distribution are studied.

\section{Experimental Work}

\section{Chemicals}

Alginic acid sodium salt (A2033) from brown algae with medium viscosity, $\gamma$-alumina nanopowder (particle size $<50 \mathrm{~nm}$ and surface area $>40 \mathrm{~m}^{2} / \mathrm{g}$ ), and calcium carbonate were supplied by Sigma-Aldrich, and de-ionized water $\left(<18.2 \mathrm{M} \Omega \mathrm{cm}^{-1}\right.$, Milli-Q Advantage A10, Millipore) were used to prepare a spinning solution for hollow fiber synthesis. Lactic acid (W261114) $\left(\mathrm{C}_{3} \mathrm{H}_{6} \mathrm{O}_{3}\right.$, Mwt $\left.90.08 \mathrm{~g} / \mathrm{mol}\right)$ purchased from Sigma-Aldrich for the preparation a coagulant aqueous solution to achieve crosslinking of alginates chains by adjusting $\mathrm{pH}$. 


\section{Preparation of spinning solution}

The spinning solution of nano alumina was prepared for hollow fiber synthesis. Calcium carbonate $(0.15 \mathrm{~g})$ was added to a de-ionized water $(82.5 \mathrm{~g})$ into two-neck flask under mechanical stirring in ultrasonic water bath for 10 minutes. $\gamma$-alumina nanopowder $(11.8 \mathrm{~g})$ was added to the calcium carbonate aqueous solution under continuous stirring and ultrasonic for 20 minutes. Sodium alginate $(5.0 \mathrm{~g})$ was then added to the prepared mixture with slow stirring in a sequence of three batches, each one introduced after total dissolution of another to obtain homogeneous solution.

\section{Synthesis of nano size hollow fiber}

Hollow fiber nano size of $\gamma$-alumina were prepared initially by degassing the spinning solution in a 1 liter stainless steel vessel under vacuum for 30 minutes and left overnight. Spinning process was carried out through spinneret dimensions $\mathrm{OD} / \mathrm{ID}=2.0 / 0.8 \mathrm{~mm}$ under 2 bar nitrogen pressure at ambient temperature. Air gap was $15 \mathrm{~mm}$ and bore liquid flow rate was $40 \mathrm{~Hz}$ taken from 5 liters spinning coagulant bath of lactic acid with $\mathrm{pH}=1.60$. The gels formation and the extent to which the inorganic particles are incorporated strongly depends on the $\mathrm{pH}$, at this $\mathrm{pH}$, a sufficient amount of calcium is released to form a stable and insoluble network [15]. The hollow fibers were left in the coagulant bath overnight. The fabricated hollow fiber was pulled out carefully from coagulant bath and attached to a rack without any stretch to achieve drying process for $48 \mathrm{~h}$. Green fiber then sintered at two thermal steps, first at $110^{\circ} \mathrm{C}$ for $1 \mathrm{~h}$ and second at different temperatures $\left(1100-1350^{\circ} \mathrm{C}\right)$ for $2 \mathrm{~h}$ at rate $5^{\circ} \mathrm{C}$ per minute. The schematic representation of spinning setup is shown in Figure 1.

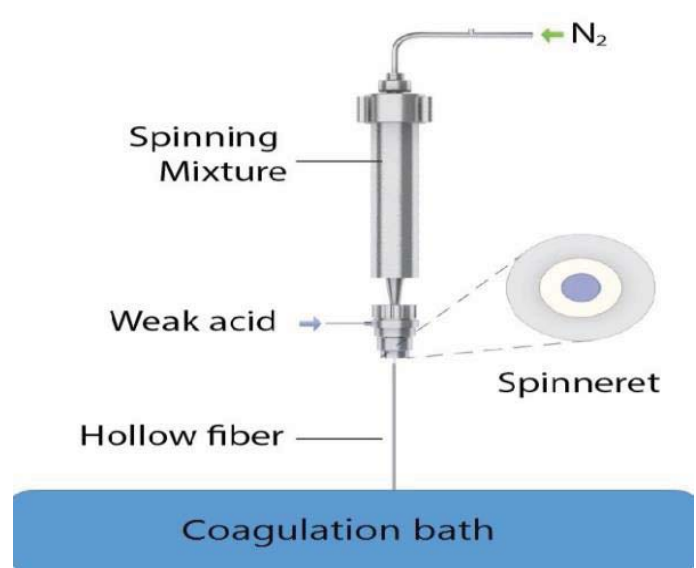

Fig.(1) Schematic representation of bio-ionic spinning under acidic condition 


\section{Characterization and Properties}

(a) Viscosity measurement

The viscosity of the nano $\gamma$-alumina spinning solution was measured at $21 \pm 1{ }^{\circ} \mathrm{C}$ with a Brookfield viscometer (DV-II+Pro) at different rotational speeds (0.5-2.0 rpm) using spindle LV4-64. Table1 shows the results of the viscosity measurement as function of the shear rate.

Table1. Viscosity of the spinning mixture

\begin{tabular}{ll}
\hline $\begin{array}{l}\text { Shear rate } \\
{\left[\mathbf{s}^{-1}\right]}\end{array}$ & Viscosity [Pa.s] \\
\hline 0.0522 & 360 \\
0.1045 & 328 \\
0.2090 & 289 \\
\hline
\end{tabular}

(b) X-ray diffraction (XRD)

The X-ray diffraction (XRD) analysis was carried out by XRD-6000 Shimadzu X-ray Diffractometer device.

(c) Scanning electron microscope (SEM)

Scanning Electron Microscopy (SEM) is a characterization technique especially useful to investigate sub-micron structures and surfaces of green and sintered nano fibers were obtained with a JEOL-JSM6010LA scanning electron microscope. All samples fractured in such a way that a flat and clean cut appears were attached to the cross section specimen holder and dried in a vacuum oven at room temperature for 12 hours. The dried samples were coated with a thin layer $(3-10 \mathrm{~nm})$ of conducting material to prevent the buildup of electrostatic charge. The green fiber was submersed in liquid nitrogen before fracturing.

(d) Thermogravimetric analysis (TGA)

Thermogravimetric analysis combined with differential scanning calorimetry analysis (TGA/DSC) was performed on a STA 449 F3 Jupiter (Netzch) fitted with a TGA-DSC sample holder. Measurements were performed under a flow of $70 \mathrm{~mL}$ min-1 synthetic air at a heating rate of $20^{\circ} \mathrm{C} \mathrm{min}^{-1}$ from room temperature to $1000{ }^{\circ} \mathrm{C}$. A temperature correction 
and sensitivity analysis using melting standards and a blank correction with an empty cup were carried out prior to the measurements. Small fragments of fibers that had been dried overnight under vacuum at $50{ }^{\circ} \mathrm{C}$ were used as samples, and their mass was determined externally.

\section{(e) Mercury Intrusion Porosimetry}

The volume of mercury intruded was measured as a function of the pressure using a Poremaster PM-33-14 (Quantachrome). The pore diameter corresponding to a certain pressure is calculated using Washburn's equation from the measured volume mercury intruded VHg versus pressure P using Matlab (Mathworks, R2014b).

\section{(f) Surface Area and Porosimetry}

Adsorption and desorption isotherms, pore size distribution, and surface area were characterized by ASAP 2020 Accelerated Surface Area and Porosimetry System from Micromeritics company according to ASTMD4222, ASTMD4641, and ASTMD3663 respectively.

\section{Results and Discussions}

\section{X-ray diffraction analysis}

XRD pattern of hollow fiber fabricated with lactic acid sintered at $1250{ }^{\circ} \mathrm{C}$ is shown in Figure 2. The starting material of fiber was gamma alumina, the crystallinity of this phase increased on heating from $600{ }^{\circ} \mathrm{C}$ to $800{ }^{\circ} \mathrm{C}$ while the gamma phase of alumina remains intact. When further heating from $900{ }^{\circ} \mathrm{C}$ to $1100{ }^{\circ} \mathrm{C}$ is applied $\gamma-\mathrm{Al}_{2} \mathrm{O}_{3}$ changed into highly crystalline $\alpha-\mathrm{Al}_{2} \mathrm{O}_{3}$ by destroying the vacancies of spinel lattice leading to structural rearrangement and also increasing the crystallite size[23]. The forming of alpha alumina below $900{ }^{\circ} \mathrm{C}$ could be occurring because of the higher number of defects present. These defects could have lowered activation energies required for the transformation by promoting the nucleation and diffusion [24]. On other hand, it was found that sintering at $1100{ }^{\circ} \mathrm{C}$ gives a few small and sharp peaks of $\alpha$-alumina started to emerge along with the amorphous hump compared with $900{ }^{\circ} \mathrm{C}$ and $1000{ }^{\circ} \mathrm{C}$, and the crystalized alumina particles commence rearrangement to form the $\alpha$-alumina phase [25]. Increase sintering to $1200{ }^{\circ} \mathrm{C}$ ensure convert to $\alpha$-alumina with a highly crystalline structure. At $1400{ }^{\circ} \mathrm{C}$, the alumina showed the same pattern as the sintered at $1200{ }^{\circ} \mathrm{C}$ excepted the intensity of XRD peaks increased, indicating that more $\alpha$-alumina crystals were distributed throughout. Ceramic hollow fiber synthesis by internal setting method in lactic acid showed a good solidarity, 
porosity, and homogenous particle distribution at $1250^{\circ} \mathrm{C}$ sintering temperature. A very brittle fiber was obtained at lower temperatures, while disordered alumina particles with low porosity was obtained at higher temperatures. The XRD peaks that indicated the presence of $\alpha$-alumina were at $2 \theta$ (Miller indices) $=25.594^{\circ}(012), 35.197^{\circ}(104), 37.804^{\circ}$ (110), $43.381^{\circ}(113), 52.588^{\circ}(024), 57.538^{\circ}(116), 59.782^{\circ}(211), 61.333^{\circ}(018), 66.547^{\circ}$ (214), $68.230^{\circ}$ and $76.909^{\circ}(119)$. It can be seen that crystallinity is high due to sintering of fine particles less than $50 \mathrm{~nm}$ from high local temperature $1250{ }^{\circ} \mathrm{C}$.

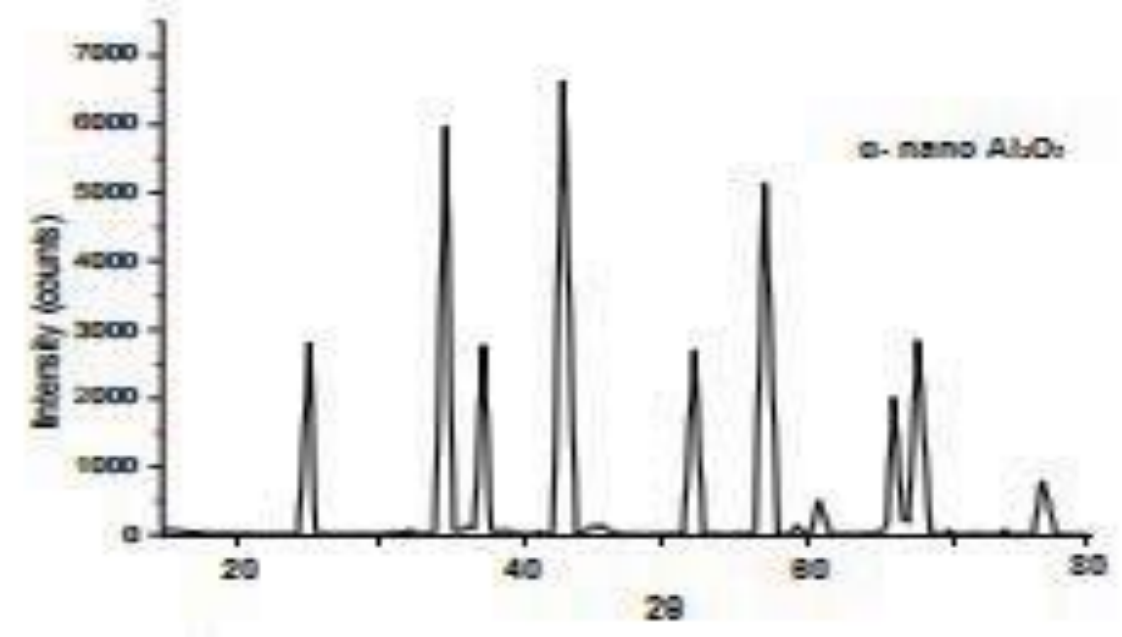

Fig.(2) XRD analysis of nano alumina fiber by internal setting gelation in lactic acid sintered at $1250^{\circ} \mathrm{C}$

\section{Microstructure and surface morphology}

The microstructure of the synthesized nano alumina hollow fiber was investigated at different sintering temperatures using scanning electron microscopy (SEM). Figure 3(a) shows the microstructure of fibers sintered at $1100{ }^{\circ} \mathrm{C}$, various grain size of alumina and wide distribution was obtained due to insufficient heat required to sinter alumina particles uniformly and incomplete change in phase from gamma to alpha and that enquires the brittleness and the attrition of fibers sintered at this temperature. Figure 3(b) shows the microstructure of fibers sintered at $1250{ }^{\circ} \mathrm{C}$, alumina particles were uniformly distributed and a porous fiber was gained, sufficient heating promoted binding between particles with less grain size. Figures $3(\mathrm{c})$ and (d) show the microstructure of fibers sintered at $1300{ }^{\circ} \mathrm{C}$ and $1350{ }^{\circ} \mathrm{C}$ respectively, it is clearly a large grains of alumina were formed associated with porosity decline at these temperature. Sintering behavior of the nano alumina starting from 
gamma phase included transformation to alpha phase is totally different from sintering of micron size alumina. The sintering of nano crystalline ceramics has focused on the issue of attaining high densities without excessive grain growth, the transparency and mechanical strength of alumina were developed by reducing the grain size [26]. It is hard to gain a quite dense ceramic with nanocrystalline grain size associated with phase transformation sequences that occur during the sintering process. The transition routes and temperatures vary accordance the particle size, chemical homogeneity, heating rate, and water vapor pressure. The low nucleation rate during the phase transformation, $\alpha-\mathrm{Al}_{2} \mathrm{O}_{3}$ colonies retreat from the matrix and the microstructure evolve into vermicular morphology containing larger scale interconnected porosity [27]. The temperature required for sintering of vermicular microstructure is above $1600{ }^{\circ} \mathrm{C}$, and to gain dense, fine grained $\alpha-\mathrm{Al}_{2} \mathrm{O}_{3}$ at low temperatures, the level of the vermicular microstructure must be reduced [31]. Several researches have been investigated pressure applying to decrease the thermodynamic and kinetic energy required for nucleation and avoiding the formation of vermicular structure, so phase transformation could be achieved at lower temperature. In the present research, the internal setting gelatin [29] for ceramic fibers fabrication offered a high chemical homogeneity for the synthesized fibers and high particle binding strength results from the high surface charging. The present technique was restricted the grain growth during sintering and achieved sintered fibers with nano particle size less than $50 \mathrm{~nm}$ at low temperature $1250{ }^{\circ} \mathrm{C}$ and ambient pressure. Figure 4 shows the surface and cross sectional SEM pictures of nano ceramic hollow fiber synthesized by internal setting gelation in lactic acid sintered at $1250^{\circ} \mathrm{C}$. The fiber has a round shape which persists after thermal treatment with a very thin wall, the fiber wall is free of macro-voids that might impede the mechanical strength of the fiber. 


\section{No.18}

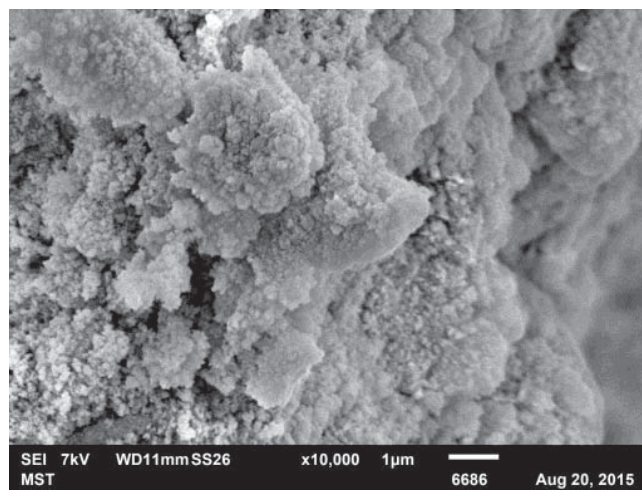

(a)

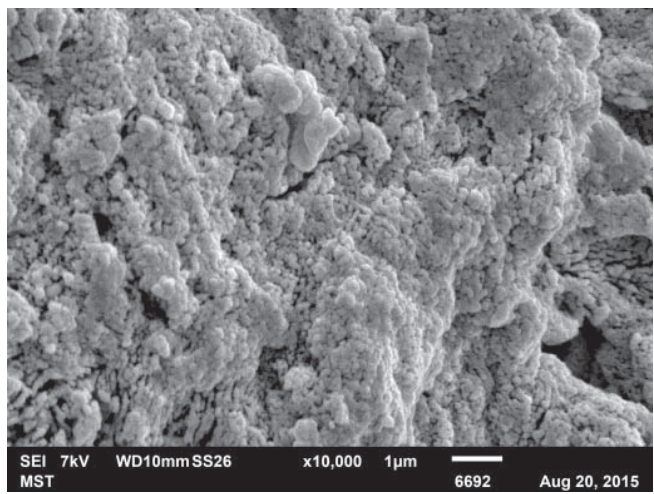

(c)

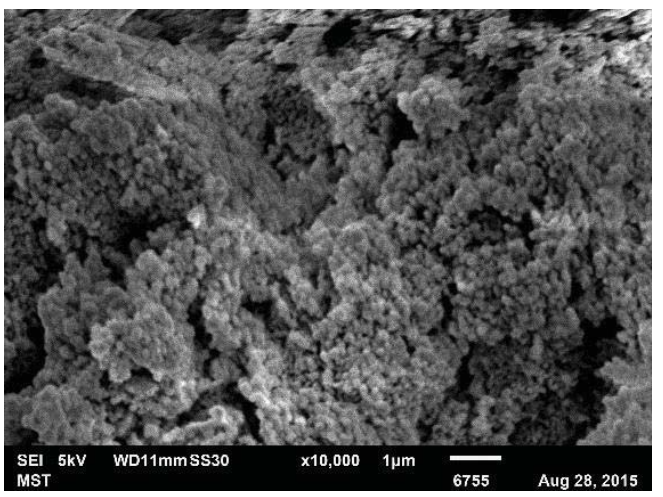

(b)

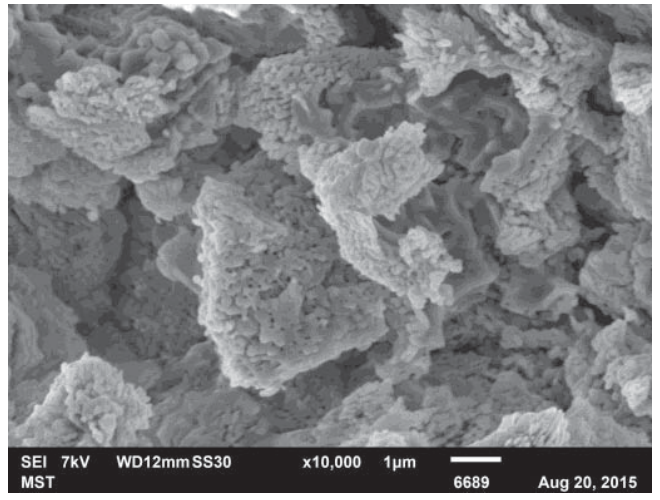

(d)

Fig. (3) SEM pictures of nano $\gamma-\mathrm{Al}_{2} \mathrm{O}_{3}$ fibers morphology at different sintering temperatures (a) $1100^{\circ} \mathrm{C}$ (b) $1250^{\circ} \mathrm{C}$ (c) $1300^{\circ} \mathrm{C}$ (d) $1350^{\circ} \mathrm{C}$

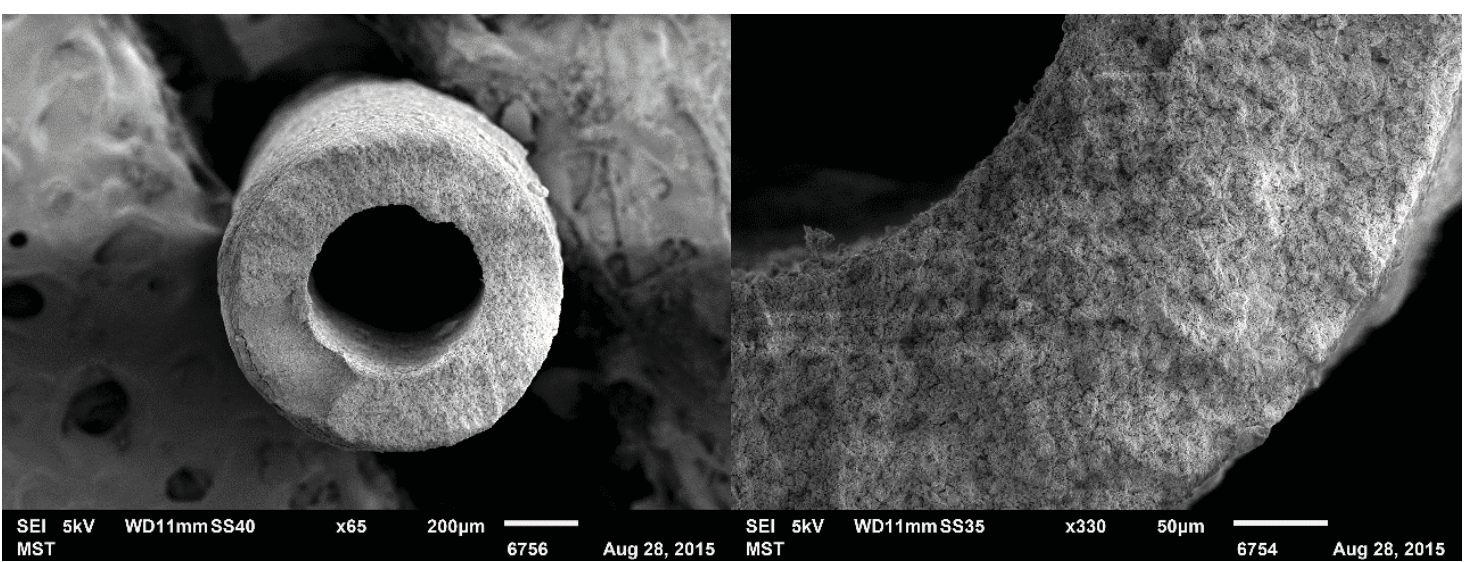

Fig. (4) Surface and cross sectional SEM pictures of nano alumina fiber by internal setting gelation in lactic acid sintered at $1250^{\circ} \mathrm{C}$ 


\section{Thermal gravimetric analysis (TGA)}

The TGA was carried out at a similar condition of fiber sintering to represent the weight loss against temperature. The TG curve presented in Figure (5) indicated that around $150{ }^{\circ} \mathrm{C}$ the onset of mass loss is found for the fiber, followed by a multistep, exothermic mass loss under heating. The first mass loss in TG curve represented the dehydration, from $150^{\circ} \mathrm{C}$ to $250^{\circ} \mathrm{C}$ around $25 \%$ weight loss was achieved in this step. The subsequent mass loss steps were concerned with the dehydration and decomposition of alginate in the fiber. Initially at $250^{\circ} \mathrm{C}$, dehydration from alginate was indicated, followed by decomposition in two overlapping steps as presented in the TG curve, without residue at the end of the experiment. The decomposition product around $400{ }^{\circ} \mathrm{C}$ was characterized as a carbonaceous material, and the mass loss was around 20\%. The total mass loss represented on TG curve was $45 \%$, and it was different from the calculated mass loss percentage based on dry fiber which is around 30\%. A species formed by the removal of a proton [29] from lactic acid (conjugate base) may co-diffused with protons and retained in the fiber. Moreover, ability of calcium ions to form complexation with lactic acid [30] could retained an extra amounts of organic materials (complexes) may adsorbed on the surface of fiber. Hence, could explain the higher mass loss in TGA compared with the theoretical calculations.

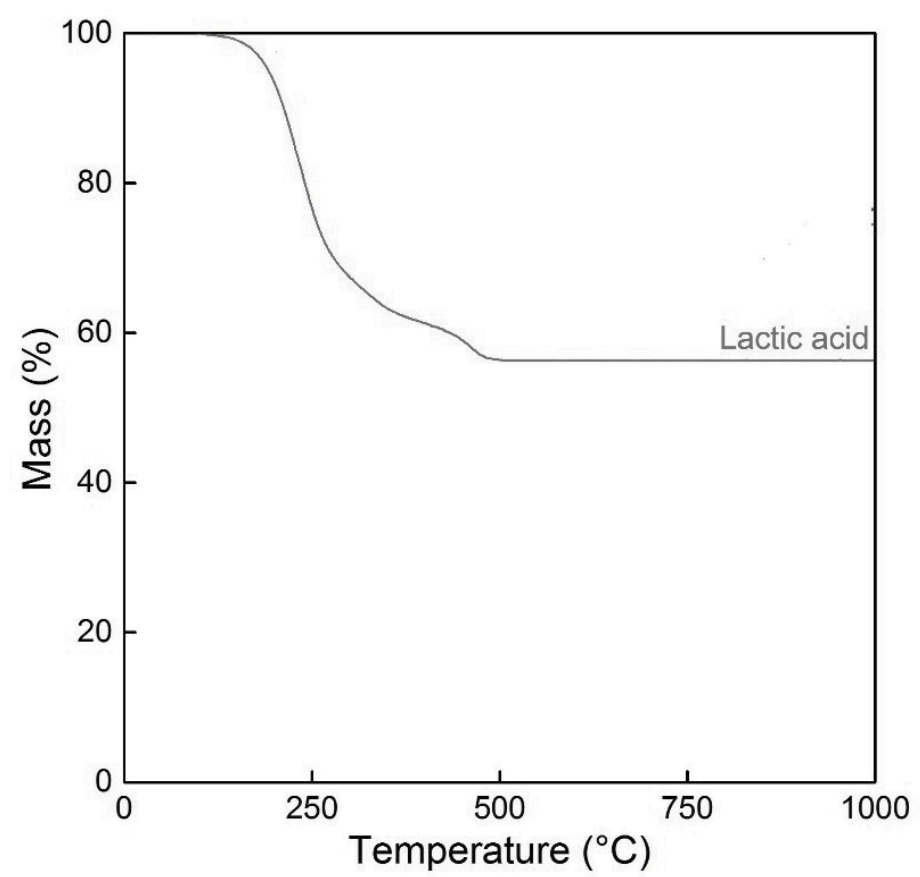

Fig. (5) TGA analysis of nano alumina fiber by internal setting gelation in lactic acid 


\section{Isotherm of nitrogen adsorption and desorption}

Figure 6 shows nitrogen adsorption and desorption isotherm for the nano alumina fiber. The adsorption curve rises gradually in the intermediate zone and shows a hysteresis loop between the adsorption and desorption curves, the hysteresis loop exhibits a relative pressure of $0.15(\mathrm{P} / \mathrm{Po})$. This behavior indicates to a mesoporous / macroporous substance. The appearance of type H-2 hysteresis loop in the isotherms indicated ink-bottle-like mesopores [31] and/or pore constrictions. This type of pores is generally formed between agglomerated primary crystallites. It was believed that intercrystallite voids were developed with randomly stacked alumina nanofibers. The type H-2 loop is broad with the desorption branch being much steeper than the adsorption branch. It is believed that this kind of loop results when there is a difference in mechanism between condensation and evaporation and that this occurs in pores with narrow necks and wide bodies or when the porous material has an interconnected pore network.

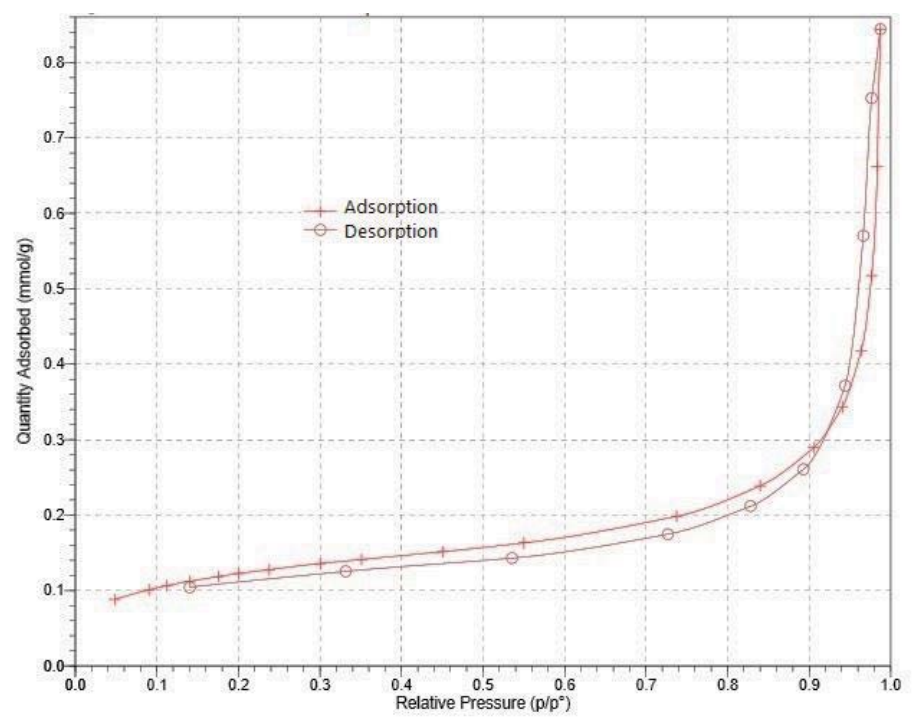

Fig. (6) Nitrogen gas adsorption and desorption isotherm for the nano alumina fiber by internal setting gelation in lactic acid sintered at $1250^{\circ} \mathrm{C}$

\section{Pore size distribution and surface properties}

The pore size distribution, surface area, and pore volume data obtained for nano size synthesized ceramic hollow fiber sintered at $1250{ }^{\circ} \mathrm{C}$ for $2 \mathrm{~h}$ in air. In general, Barrett, Joyner and Halenda (BJH) method was applied to determine the pore size distribution for mesopore consisting materials. This method is based on the Kelvin equation and modified 
to include multilayer adsorption. The BJH pore size distribution curves of adsorption and desorption are reproduced in Figure 7(A) and 7(B) respectively. The pore size distribution is wide and pore size lies between 1 and $100 \mathrm{~nm}$. The pore size distribution curve was mostly fallen in mesopores scale and extended to macropores. A broad distribution behavior was obtained, type H-2 can be found in many porous adsorbents and is believed to occur [32] in systems where the distribution of pore sizes and pore shapes are broad. The hysterics loop indicating a broad pore size distribution with uniform size and shape, due to the high homogeneity and surface charge [15] generated from the internal diffusion method used in the fabrication of fiber. BJH adsorption and desorption average pore diameter (4V/A) $14.4408 \mathrm{~nm}$ and $17.7124 \mathrm{~nm}$ respectively. Single point surface area at $\mathrm{p} / \mathrm{p}^{\circ}=0.30$ is $9.268 \mathrm{~m}^{2} / \mathrm{g}$. Single point adsorption total pore volume of pores less than $117.8189 \mathrm{~nm}$ diameter at $\mathrm{p} / \mathrm{p}^{\circ}=0.983$ is $0.023 \mathrm{~cm}^{3} / \mathrm{g}$. Figure $7(\mathrm{C})$ shows the volume-based pore size distribution of sintered fibers by mercury intrusion. The sintered fiber results in a bellshaped pore size distribution with a median interior pore size of $20 \mathrm{~nm}$ and exterior of $50 \mathrm{~nm}$.
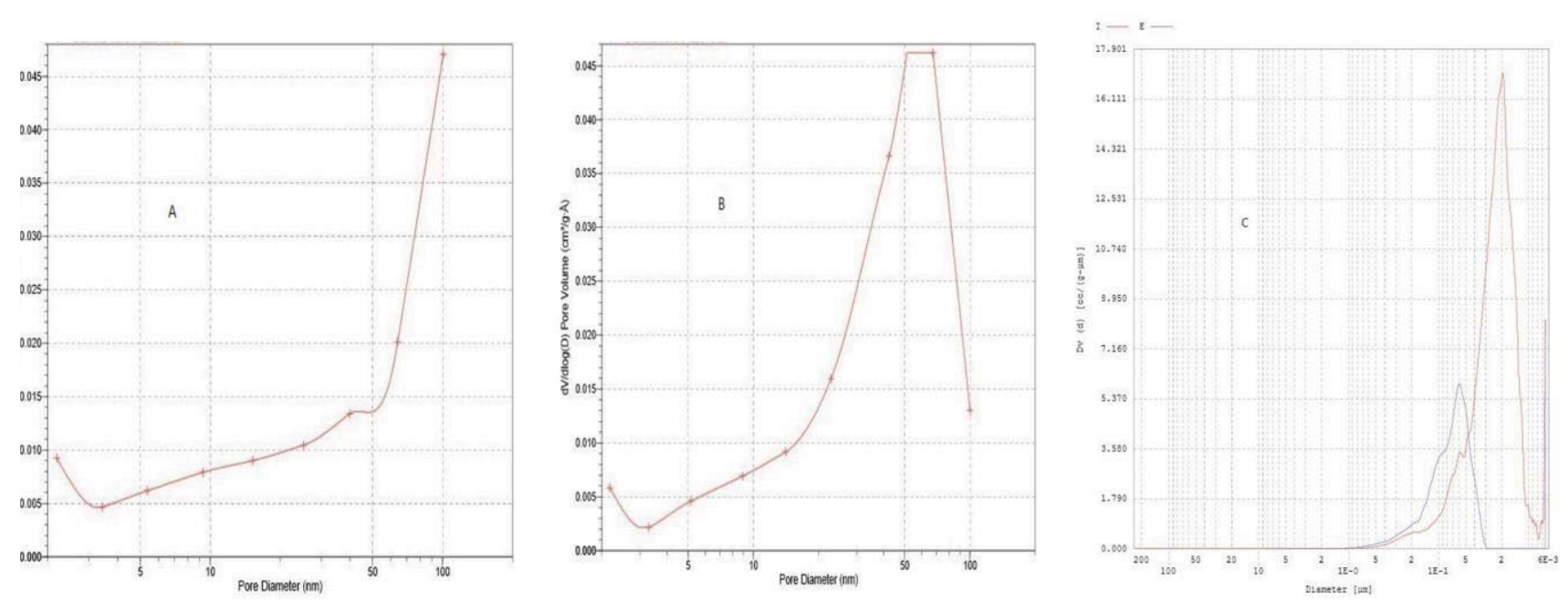

Fig. (7) Pore size distribution of nano alumina fiber by internal setting gelation in lactic acid sintered at $1250^{\circ} \mathrm{C}(\mathrm{A})$ adsorption (B) desorption (C) Mercury intrusion 


\section{Conclusions}

Nano porous ceramic hollow fibers membranes can be fabricated by using the bio ionic gelation- internal setting method. The optimum sintering temperature was $1250{ }^{\circ} \mathrm{C}$ for $2 \mathrm{~h}$, gamma phase was completely transformed to alpha phase. A uniform dispersed nano alumina particles was obtained, high ordered divalent cations generation from inside spinning mixture through the bulk led to resultant morphology. Thermal treatment detected by TGA was classified into two steps, dehydration from $150^{\circ} \mathrm{C}$ to $250^{\circ} \mathrm{C}$, and dehydration and decomposition of alginate in the fiber from $250^{\circ} \mathrm{C}$ to $400^{\circ} \mathrm{C}$. The nitrogen isotherm behavior indicates to a mesoporous / macroporous substance, an appearance of type $\mathrm{H}-2$ hysteresis loop in the isotherms indicated ink-bottle-like mesopores. A small mean pore size $<20 \mathrm{~nm}$ of the fibers was referred to high binding forces results from high surface generation. 


\section{$\underline{\text { References }}$}

1. L. Jiansheng, W. Lianjun, H. Yanxia, L. Xiaodong, S. Xiuyun (2005), Preparation and characterization of A12O3 hollow fiber membranes, J. Memb. Sci. 256, 1-6.

2. X. Tan, S. Liu, K. Li (2001), Preparation and characterization of inorganic hollow fiber membranes, J. Memb. Sci. 188, 87-95.

3. C. Yang, W. Li, S. Zhang, L. Bi, R. Peng, C. Chen, et al. (2009), Fabrication and characterization of an anode-supported hollow fiber SOFC, J. Power Sources. 187, 90-92.

4. H.C. Aran, J.K. Chinthaginjala, R. Groote, T. Roelofs, L. Lefferts, M. Wessling, et al. (2011), Porous ceramic mesoreactors: A new approach for gas-liquid contacting in multiphase microreaction technology, Chem. Eng. J. 169, 239-246.

5. A. Julbe, V. Rouessac, J. Durand, A. Ayral (2008), New approaches in the design of ceramic and hybrid membranes, J. Memb. Sci. 316, 176-185.

6. A. Julbe, D. Farrusseng, C. Guizard (2001), Porous ceramic membranes for catalytic reactors - Overview and new ideas, in: J. Memb. Sci., pp. 3-20.

7. X. Zhang, B. Lin, Y. Ling, Y. Dong, D. Fang, G. Meng, et al. (2010), Highly permeable porous YSZ hollow fiber membrane prepared using ethanol as external coagulant, J. Alloys Compd. 494, 366-371.

8. X. Zhang, D. Fang, B. Lin, Y. Dong, G. Meng, X. Liu (2009), Asymmetric porous cordierite hollow fiber membrane for microfiltration, J. Alloys Compd. 487, 631-638.

9. R. Terpstra, J. Van Eijk, F. Feenstra (1998), Method for the production of ceramic hollow fibres, US Pat. 5,707,584.

10. J. Smid, C.G. Avci, V. Günay, R.A. Terpstra, J.P.G.M. Van Eijk (1996), Preparation and characterization of microporous ceramic hollow fibre membranes, J. Memb. Sci. 112, 8590.

11. L. Liu, X. Tan, S. Liu, Yttria (2006), Stabilized Zirconia Hollow Fiber Membranes, J. Am. Ceram. Soc. 89, 1156-1159.

12. J. de Jong, N.. Benes, G.. Koops, M. Wessling (2004), Towards single step production of multi-layer inorganic hollow fibers, J. Memb. Sci. 239, 265-269.

13. P. de Wit, E.J. Kappert, T. Lohaus, M. Wessling, A. Nijmeijer, N.E. Benes (2015), Highly permeable and mechanically robust silicon carbide hollow fiber membranes, J. Memb. Sci. 475, 480-487. 
14. S. Shukla, P. de Wit, M.W.J. Luiten-Olieman, E.J. Kappert, A. Nijmeijer, N.E. Benes (2015), Synthesis of Porous Inorganic Hollow Fibers without Harmful Solvents, ChemSusChem. 8, 251-254.

15. H.Q. Hussein, P. de Wit, E.J. Kappert, and N.E. Benes (2015), Sustainable Route to Inorganic Porous Hollow Fibers with Superior Properties, ACS Sustainable Chem. Eng. 3, 3454-3460.

16. J. H. Fendler (Ed) (1998), Nanoparticles and Nanstructured Films, Wiley VCHverlag, , Weinheim.

17. J. R. Groza and R.J. Dowding (1996), Nanoparticulate Materials Densification, NanoStr. Mater., 7(7), 749-68.

18. Legros C., Carry C., Bowen P., Hofman H., Sintering of a transition alumina: Effects of phase transformation, powder characteristics and thermal cycle, Journal of the European Ceramic Society, 19 (1999) 1967-1978

19. Eduardo, J. Gonzalez, Grady White, and Lanhua Wei Ceramics Division National Institute of Standards and Technology Gaithersburg, MD 20899.

20. Lioa, S. C, Chen, Y. J, Kear, B. H, \& Mayo, W. E. (1998), High Pressure / Low Temperature Sintering of Nanocrystalline Alumina"Nano Structured Materials , 10(6).

21. Bo Wanga, b, Zhiping Lai, Finger-like voids induced by viscous fingering during phase inversion of alumina/PES/NMP suspensions, J. Membr. Sci. 2012, 405 -406, 275- 283.

22. Benjamin F.K. Kingsbury, K. Li, A morphological study of ceramic hollow fibre membranes, J. Membr. Sci. 2009, 328, 134-140.

23. L. A. Avinash Chunduri, Tanu Mimani Rattan, Muralikrishna Molli, and Venkataramaniah Kamisetti (2014), Single step preparation of nano size gamma alumina exhibiting enhanced fluoride adsorption, Mater. Express, Vol. 4(3).

24. S. Liu, L. Zhang, L. An, W. Fei, and H. Heinrich (2005), Phase transformation of mechanically milled nano-sized $\gamma$-alumina; J. Am. Ceram. Soc. 88, 2559.

25. Khamirul Amin Matori, Loy Chee Wah, Mansor Hashim, Ismayadi Ismail and Mohd Hafiz Mohd Zaid (2012), Phase Transformations of $\alpha$-Alumina Made from Waste Aluminum via a Precipitation Technique", Int. J. Mol. Sci.,13, 16812-16821.

26. A Krell, P Blank, H Ma, T Hutzler, MPB Bruggen, R Apetz (2003), Transparent sintered corundum with high hardness and strength, J. Am. Ceramics Soc., 86 (1), 12-18.

27. Eduardo, J. Gonzalez, Grady White, and Lanhua Wei (2000), Effects of microstructural 
evolution on the thermal conductivity of $\alpha-\mathrm{Al}_{2} \mathrm{O}_{3}$ prepared from nano-size $\gamma-$ $\mathrm{Al}_{2} \mathrm{O}_{3}$ powder, Journal of Materials Research, 15 (3) , 744-750.

28. E. J. Gonzalez, B. Hockey, and G. J. Piermarini (1996), Materials and Manufacturing Processes 11 (6), 951-967.

29. Zumdahl, Stephen S., \& Zumdahl, Susan A. (2007), Chemistry, Houghton Mifflin, $7^{\text {th }}$ edition.

30. Bazin, H.; Descotes, G.; Bouchu, A.; Petit-Ramel, M. (1995), Comparison of calcium complexation of some carboxylic acids derived from D glucose and D -fructose. Can. J. Chem., 73, 1338-1347.

31. C. Sangwichien, G. L. Aranovich, and M. D. Donohue (2002), Density Functional Theory Predictions of Adsorption Isotherms with Hysteresis Loops, Colloids Surf., A: Physicochem. Eng. Aspects 206 (1-3), 313-20.

32. F. Rouquerol, J. Rouquerol, K. Sing (1999), Adsorption by Powdors and Porous Solids Principles, Methodology and Applications, Academic Press, San Diego, CA. 